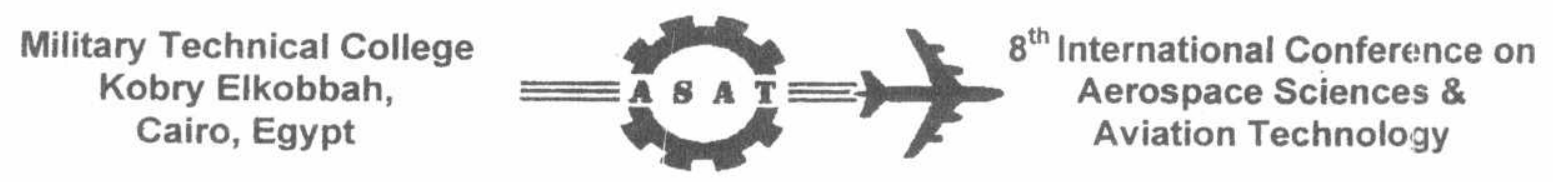

\title{
PERFORMANCE OF ARTILLERY PROJECTILES WITH BASE BLEED UNIT
}

\author{
A. Zaki*, M.S. Abdel-Kader**, and H. Yakout**
}

\section{ABSTRACT}

Range extension of artillery projectiles has always been a basic requirement of the user in order to shoot the enemy targets at longer distances. Base bleeding $(\mathrm{BB})$ is one of the concepts used to decrease air resistance during projectile flight in air and, consequently, increase range.

This paper studies the effect of BB on projectile range and evaluates BB unit ballistic performance. The BB grain shape investigated herein is the modified star grain shape. Instantaneous burnt surface of the grain is calculated using a newly developed approach which can be readily used with other grain shapes. The relation between the $\mathrm{BB}$ unit and the projectile ballistic shape is discussed. The effect of projectile spinning on burning rate of $\mathrm{BB}$ grain is also studied. It is concluded that the effect of BB projectile spinning on the range is very limited.

A parametric study is performed to study the effect of grain geometry, initial firing angle, and $\mathrm{BB}$ grain burning rate on the $\mathrm{BB}$ projectile range. The range of $\mathrm{BB}$ projectile is extended by about $17 \%$ of the total range of the same projectile with dummy BB.

\section{INTRODUCTION}

Long ranges of artillery projectiles has always been of main concern to weapons and ammunition designers. The range of an artillery projectile depends on many factors which are divided into three main groups as follows: (i) increase of muzzle velocity, (ii) rocket assistance, and (iii) ballistic improvements [1]. The third group involves drag reduction, aerodynamic amendments, or use of subcaliber projectiles. Drag reduction is obtained by decreasing air resistance components acting on the projectile during its flight. The air resistance is divided into three main components, which are the head resistance (nose drag), the viscous (skin friction) drag, and base drag. The last component represents an appreciable portion of the total drag [2], specially at subsonic and transonic regions of projectile velocity. Figure (1)

\footnotetext{
- Assistant Lecturer, "'Associate Prof., and '- Lecturer, Department of Aerospace Engineering, M.T.C, Cairo, Egypt.
} 
illustrates the percentages of the drag components versus Mach number relative to each other.

The ammunition designers seek to decrease wake zone behind the projectile, or to raise the afterbody pressure. The wake zone is normally decreased by beveling (boattailing) the projectile end. The pressure in this zone is raised by bleeding of gases from the projectile bottom (base flow) using a BB unit.

A simple model was used by Chow [2] to simulate the flow

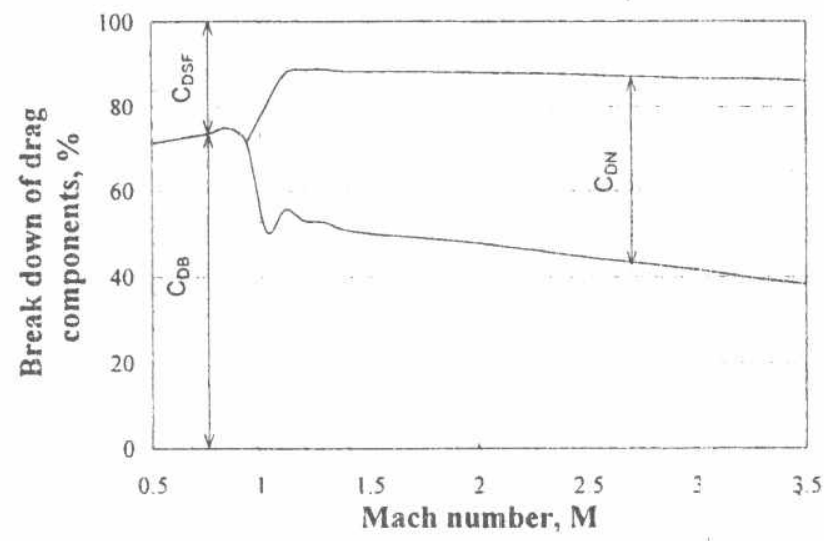

Fig. 1 Breakdown of drag coefficients of artillery projectile of gases from base of supersonic projectiles. It was shown that the gas flow through the base-wake region is divided into three regimes, which depend on the stagnation pressure (chamber pressure of the bleeding unit) and Mach number of external flow, as shown in Fig. (2). In regime $\mathrm{I}$, the base pressure ratio $\left(P_{B} / P_{\infty}\right)$ reaches its maximum value without generating a thrust component which may result from penetration of wake end. In regime II, $P_{B} / P_{\infty}$ decreases to its critical lower limit. In regime $I I I, P_{B} / P_{\infty}$ increases with the increase of chamber pressure, but there is a thrust component due to penetration of the wake end by the gases supersonic flow. It is now

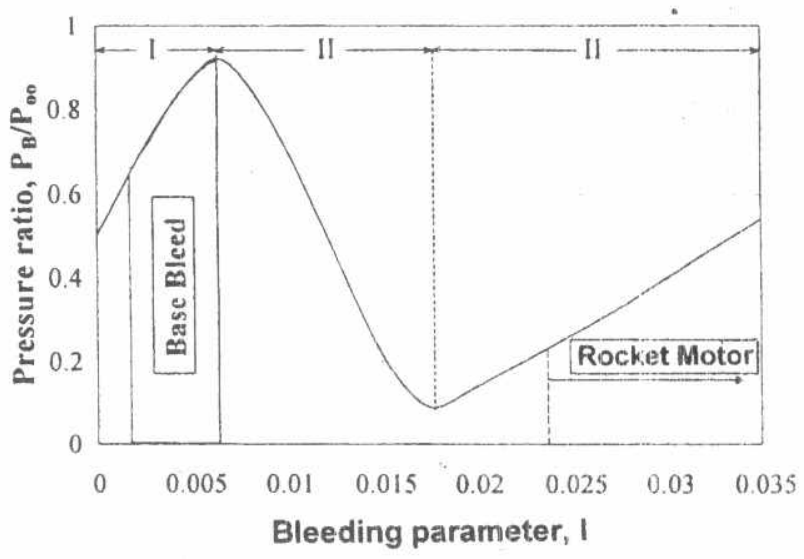

Fig.2 Pressure ratio versus bleeding parameter [3] obvious that the first regime is the best flow pattern to choose for burnt gases of BB unit.

\section{MODELING OF BB DRAG REDUCTION}

The total drag coefficient is the sum of the three drag coefficients. That is:

$$
\mathrm{C}_{\mathrm{D}}(\mathrm{M}, \mathrm{Re})=\mathrm{C}_{\mathrm{DN}}(\mathrm{M})+\mathrm{C}_{\mathrm{DSF}}(\mathrm{M}, \mathrm{Re})+\mathrm{C}_{\mathrm{DA}}(\mathrm{M}) \text {, }
$$

where, $C_{D N}, C_{D S F}$ and $C_{D A}$ are the nose, viscous, and afterbody drag coefficients, respectively. The afterbody drag is the sum of the base pressure drag $\mathrm{C}_{\mathrm{DBP}}$ and the boat-tail drag $\mathrm{C}_{\mathrm{DBT}}$. $\mathrm{A}$ combination of two drag models will be used in order to predict drag, coefficients at Mach numbers ranging from 0 to $3.5[4]$. 
In case of $B B$, the total drag is reduced by a value denoted by $\Delta C_{D}$. Thus, the total drag coefficient is given by the following equation:

$$
\mathrm{C}_{\mathrm{D}}{ }^{*}(\mathrm{M})=\mathrm{C}_{\mathrm{D}}(\mathrm{M})-\Delta \mathrm{C}_{\mathrm{D}}(\mathrm{M}) \text {. }
$$

According to Bowman-Clayden's empirical formula [5], the course of base drag reduction may be assumed as an exponential function of the form:

$$
\Delta \mathrm{C}_{\mathrm{D}}=\mathrm{C}_{\mathrm{DBP}}\left(1-\mathrm{e}^{-\mathrm{J}}\right) \text {. }
$$

The bleeding parameter $\mathrm{I}$ is defined as the ratio between the mass flow rate of the burnt gases from $\mathrm{BB}$ exit area $\left(\mathrm{m}^{\circ} \mathrm{N}\right)$ to the mass flow rate of air at the projectile base $\left(m_{B}{ }_{B}\right)$, with the air stream lines assumed to be attached to the projectile base, i.e:

$$
I=\frac{\dot{m}_{N}}{\dot{m_{B}}} .
$$

Assuming that the burnt mass of the BB grain per unit time $\left(m_{b}{ }_{b}\right)$ is equal to the mass flow rate of burnt gases from $B B$ exit area $\left(m_{N}\right)$, the bleeding parameter can be expressed as:

$$
I=\frac{\dot{m}_{b}}{\dot{m}_{B}}=\frac{\rho_{s} \cdot U \cdot S(t)}{\rho_{n} \cdot v \cdot A_{B}} .
$$

where $\rho_{s}$ is the BB grain density, $U$ is the grain composition burning rate, $S(t)$ is the instantaneous burnt surface, $\rho_{\infty}$ is the upstream air density, $v$ is the projectile velocity, and $A_{B}$ is the base area of the $B B$ unit.

It is seen from equation (3) that the base drag reduction increases with the increase of the bleeding parameter. But this increase is limited to a certain value of the bleeding parameter $I_{\lim }$ after which the base flow will be in the second regime [cf. Fig. (2)]. For this reason, Jaramaz and Injac introduced the function $C_{k}$ to decrease $\Delta C_{D}$ in case the bleeding parameter exceeds $\mathrm{l}_{\mathrm{im}}$. Thus, the equation of drag reduction will have the form [6]:

$$
\Delta \mathrm{C}_{\mathrm{D}}=\mathrm{C}_{\mathrm{DBP}}\left(1-\mathrm{e}^{-\mathrm{t}, J}\right) \mathrm{C}_{\mathrm{K}} \text {. }
$$

where

$$
\begin{aligned}
& C_{\mathrm{K}}=1 \text {, } \\
& 1 \leq I_{\text {lim }}, \\
& \mathrm{C}_{\mathrm{K}}=1-\left(\frac{\mathrm{I}}{\mathrm{I}_{\text {lim. }}}-1\right)^{2} \mathrm{C}_{\text {lim. }}, \quad \quad \mathrm{I} \text { l lim. }
\end{aligned}
$$

where $C_{\text {lim }}$ is a constant determined for each $B B$ projectile. Function $J(M)$ is determined from experimental measurements of the drag coefficients of a projectile with and without $B B$ at low angle of fire $\left(\theta_{0}=20^{\circ}\right)$. Then the correctness of function $J(M)$ is checked at the angle of fire which gives maximum range $\left(\theta_{0}=48^{\circ}-50^{\circ}\right)$. 
In this method the base bleed chamber pressure is assumed. Then, it is recalculated from the equality of $\left(m_{b}^{\circ}\right)$ and $\left(m_{N}{ }_{N}\right)$ according to the following procedures:

1 - Assume any value of pressure $P_{B}$, then $P_{c h}$ will be $P_{B}+\Delta P$, where $P_{B}$ is the base pressure, $P_{c h}$ is the $B B$ chamber pressure and $\Delta P$ is the pressure difference.

2 - Calculate the burning rate and the instantaneous burnt surface.

3 - Calculate $\mathrm{m}_{\mathrm{b}}^{\circ}$ and $\mathrm{m}_{\mathrm{B}}{ }_{\mathrm{B}}$, then predicte bleeding parameter.

4- Predicte the function $J(M)$. The base drag reduction $\Delta C_{D}(M)$ is obtained experimentally using a tracking radar. $\Delta \mathrm{C}_{D}(M)$ is correlated to get a polynomial function as follows:

$$
\Delta C_{D}(M)=c_{o}+c_{1} M+c_{2} M^{2}+c_{3} M^{3}+c_{4} M^{4}
$$

Then, function $\mathrm{J}$ is calculated from Eq. (6):

$$
J(M)=\frac{1}{I} \cdot \ln \left(1-\frac{\Delta C_{D}(M)}{C_{D B P}(M)}\right) \text {. }
$$

5 - Estimate the drag reduction.

6 - Apply the basic equation of base drag coefficient:

$$
P_{B}=P_{\infty}\left[1-\frac{1}{2} k_{\text {nir }} \cdot M_{\infty}^{2}\left(C_{D B P}-\Delta C_{D}\right)\left(\frac{D}{D_{B}}\right)^{2}\right] \text {. }
$$

where $k_{\text {air }}$ is the specific heat ratio

7 - Check the type of gases flow. The flow is subsonic if:

$$
\text { and supersonic if: } \quad \frac{\mathrm{P}_{\mathrm{B}}}{\mathrm{P}_{\mathrm{ch}}} \leq\left(\frac{2}{\mathrm{k}+1}\right)^{\left(\frac{\mathrm{k}}{k+1}\right)} \text {. }
$$

In eqs.(11), $k$ is the specific heat ratio of the burnt gases.

8 - The gases flow rate is calculated according to the type of flow from the following equations:

a) In case of subsonic flow:

$$
\dot{\mathrm{m}}_{\mathrm{N}}=\rho_{\mathrm{G}} \mathrm{A}_{1}\left(\frac{\mathrm{P}_{\mathrm{B}}}{\mathrm{P}_{\mathrm{ch}}}\right)^{\frac{1}{k}} \sqrt{\frac{2 \mathrm{k}}{\mathrm{k}-1} \mathrm{R}_{\mathrm{G}} \mathrm{T}_{\mathrm{G}}\left[1-\left(\frac{\mathrm{P}_{\mathrm{B}}}{\mathrm{P}_{\mathrm{ch}}}\right)^{\frac{k-1}{k}}\right]},
$$

b) In case of supersonic flow:

$$
\dot{\mathrm{m}}_{\mathrm{N}}=\frac{\gamma(\mathrm{k}) \cdot \mathrm{P}_{\mathrm{cl}} \mathrm{A}_{\mathrm{t}}}{\sqrt{\mathrm{R}_{\mathrm{G}} \mathrm{T}_{\mathrm{G}}}}
$$

where $\rho_{G}$ is the burnt gases density, $A_{t}$ is the exit area of base bleed unit, $R_{G}$ is the burnt gas constant, $T_{G}$ is the explosion temperature of the burnt gases, and $\gamma$ is a function of $k$ given by the following equation:

$$
\gamma(\mathrm{k})=\sqrt{\mathrm{k}}\left(\frac{2}{\mathrm{k}+1}\right)^{\frac{\mathrm{k}+1}{2(\mathrm{k}-1)}} .
$$


The rate of burnt gases flow from the exit area of $B B$ is equal to the burnt mass of the grain per unit time $\left(m_{b}^{\circ}=m_{N}{ }_{N}\right)$. Thus, the value of $P_{c h}$ can be recalculated and compared with the initial value using the following equations:

a) for subsonic flow,

b) for supersonic flow,

$$
P_{c h}^{*}=\frac{P_{B}{ }^{\frac{k-1}{k}}}{2}+\frac{\sqrt{P_{B} \frac{2(k-1)}{k}+2 \frac{\dot{m}_{b} R_{G} \cdot T_{G}(k-1)}{A_{1}{ }^{2} \cdot P_{B}\left(\frac{2}{k}\right) \cdot k}}}{2} .
$$

$$
\mathrm{P}_{\mathrm{ch}} \cdot=\frac{\dot{\mathrm{m}}_{\mathrm{b}} \sqrt{\mathrm{R}_{\mathrm{G}} \cdot \mathrm{T}_{\mathrm{G}}}}{\gamma \cdot \mathrm{A}_{1}},
$$

where $P^{*}$ ch is the new calculated chamber pressure from equality of the two mass flow rates $m_{b}{ }_{b}$ and $m_{N}{ }_{N}$. If $\left|P_{c h}-P^{*}{ }_{c h}\right| \leq \varepsilon P$, where $\varepsilon P$ is the acceptable error in chamber pressure prediction, then the solution is stopped ancl the estimated drag reduction coefficient is subtracted from the predicted total drag coefficient.

\subsection{Burnt Surface of BB Grain}

The changes in burnt surface depend on the grain shape. Calculation of the burnt surface for this grain shape will be determined as a function of the infinitesimal burnt layer $(\Delta E)$ of the surface that is exposed to burning. Burning rate at any time will be calculated according to the following equation:

$$
\mathrm{U}=\frac{\Delta \mathrm{E}}{\Delta \mathrm{t}},
$$

where $\Delta t$ is the time interval during which the infinitesimal layer will burn. Thus, at any time the burnt thickness $E(t)$ will be:

$$
\mathrm{E}(\mathrm{t})=\mathrm{E}(\mathrm{t}-\Delta \mathrm{t})+\mathrm{U} \cdot \Delta \mathrm{t} \text {. }
$$

Calculation of the instantaneous burnt surface in case of the modified star grain is based on the mathematical equations of the burnt contours length with time. Referring to Fig. (3), the quarter of the modified star grain is defined in the $X-Y$ coordinate system, and the length of contour ABCD is calculated with time [i.e. as a function of the burnt thickness $E(t)$ ]. The length of contour $A B C D$ is multiplied by twice the number of the star points; thus, the burnt perimeter is determined. The burnt surface is calculated when multiplying the perimeter by the total grain length $(L)$. Length of contour $A B$ is determined as an arc of a circle, with the center $(0, c)$ and the equation:

$$
y-c=\sqrt{\left(r_{f}+E\right)^{2}-x^{2}} .
$$

The segment $B C$ is calculated by determination of coordinates of points $B$ and C. Then the following equation will be applied:

$$
\overline{\mathrm{BC}}=\sqrt{\left(\mathrm{X}_{\mathrm{B}}-\mathrm{X}_{\mathrm{C}}\right)^{2}+\left(\mathrm{Y}_{\mathrm{B}}-\mathrm{Y}_{\mathrm{C}}\right)^{2}} \text {. }
$$


The segment $C D$ is determined from the coordinates of points $C$ and $D$. Then the following equation will be applied:

$\overline{C D}=\sqrt{\left(X_{C}-X_{D}\right)^{2}+\left(Y_{C}-Y_{D}\right)^{2}}$

\subsection{Burning Rate of BB Grain}

The dependence of burning rate on chamber pressure of BB unit is given by the following famous equation of burning [7]:

$$
\mathrm{U}_{\mathrm{o}}=\mathrm{U}_{1} \cdot \mathrm{P}_{\mathrm{ch}}{ }^{\alpha} \text {, }
$$

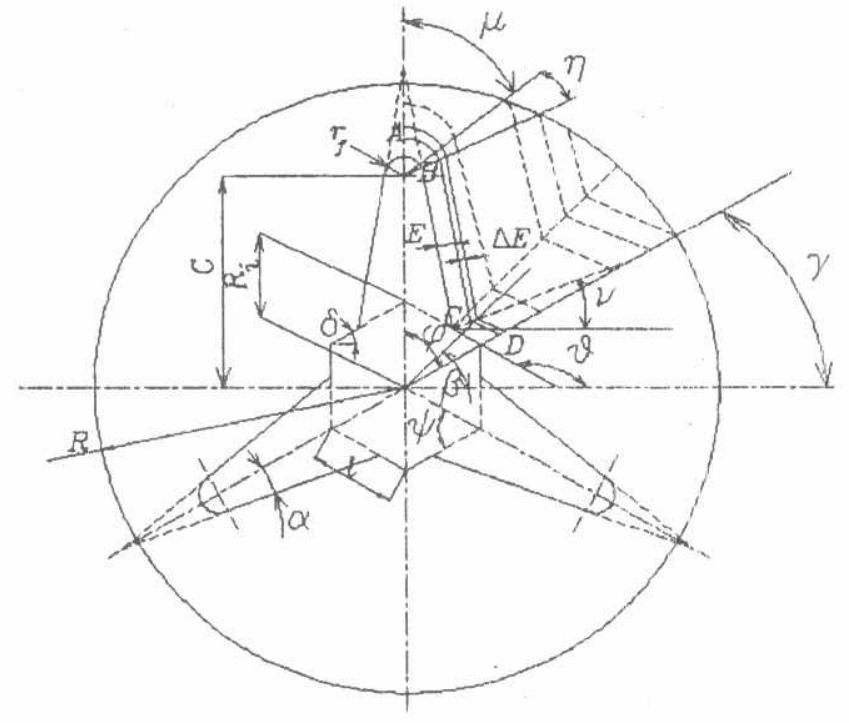

Fig.3 Geometry of the modified star grain

where $U_{1}$ is the unit burning rate $[\mathrm{mm} / \mathrm{s} / \mathrm{Pa}], P_{c h}$ is the base bleed chamber pressure [Pa], and $\alpha$ is the pressure exponent. Equation (22) is applied in case of static burning, but $\mathrm{BB}$ grain is burnt during projectile spinning during flight. So, burning rate augmentation $\left(U / U_{0}\right)$ will be determined against the projectile spinning rate through a mathematical model introduced by Sturm and Reichenbach [8].

From the point of view of the phalanx model, Sturm and Reichenbach postulated that the phalanx flame may proceed completely around the oxidizer particle before its full consumption [8]. The small-size oxidizer particles will be separated from the propellant matrix by a thin film of the gaseous products. In case of non-spinning projectiles, these particles will be freed by the effect of the drag force of gas flow generated from the burnt surface of solid propellant. But, in case of spinning projectiles, this particle will be retained at the propellant surface under the force resulting from the acceleration field due to projectile spinning. The retention of the particles will be continued until the body force $\left(F_{b}\right)$ resulting from projectile rotation and the drag force $\left(F_{d}\right)$ due to flow of gases become equal [cf. Fig. (4)].

From Fig. (4), it is obvious that the particle is retained in case of projectile spinning and consumed by its decomposition until a certain critical diameter, $d_{p c}$ is reached, at which the particle starts to free itself.

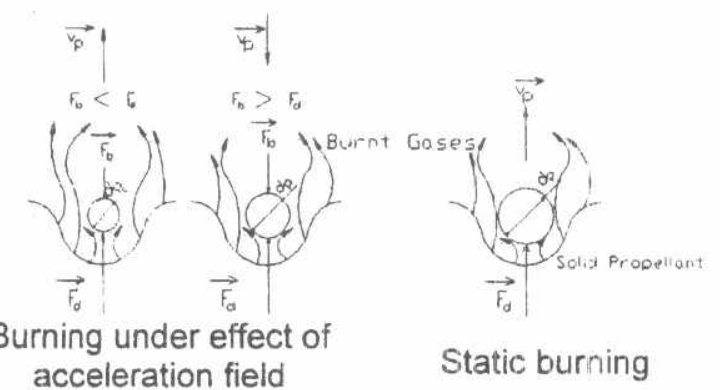

Fig 4 Forces acting on the ammonium perclorate particle 
Heat balance equation at the burnt surface was introduced by Sturm and Reichenbach in the following form:

$\begin{aligned} & \text { Energy per unit area } \\ & \text { per unit time needed } \\ & \text { for gasification of } \\ & \text { the propellant }\end{aligned} \quad \begin{aligned} & \text { Energy per unit area } \\ & \text { per unit time supplied } \\ & \text { due to burning in no } \\ & \text { acceleration field }\end{aligned}$
$\begin{aligned} & \text { Energy per unit area } \\ & \text { per unit time supplied }\end{aligned}$
$\begin{aligned} & \text { to the surface due to } \\ & \text { ammonium perclorate } \\ & \text { retention }\end{aligned}$

$$
\rho_{s} \cdot U \cdot h_{v}=\rho_{s} \cdot U_{0} \cdot h_{v}+\rho_{s} \cdot U \cdot h_{c}\left(W_{o} f J_{f}\right),
$$

where $h_{v}$ is the energy required to gasify a unit mass of propellant, $\rho_{s}$ is the solid propellant density, $U_{0}$ is the static burning rate, $W_{0}$ is the weight percent of small ammonium perclorate particles, $h_{c}$ is the energy released due to combustion of unit mass of the oxidizer, $f$ is the fraction of energy release transferred to the propellant surface and $J_{f}$ is the fraction of additional small size oxidizer particles which decomposes on the propellant surface. The previous equation may be also written in the following form:

$$
\frac{U}{U_{0}}=\left(1-\frac{w_{0} \cdot h_{c}}{h_{v}} \cdot f \cdot J_{r}\right)
$$

The term $\left(W_{0} h_{d} / h_{v}\right)$ depends on the propellant composition and is denoted by the symbol $\eta$. Thus the equation of burning rate augmentation will be:

$$
\frac{U}{U_{0}}=\left(1-\eta \cdot f \cdot J_{f}\right)^{-1} \text {. }
$$

It is apparent that the increase in the term ( $\eta$.f. $J_{f}$ ) leads to increase in burring rate augmentation. The parameter $f$ represents the energy fraction, convicted heat, transferred to the propellant surface due to decomposition of oxidizer particles. The parameter $J_{f}$ is the function of additional small size ammonium perclorate mass which decomposes on the propellant surface due to forces resulting from the acceleration field. The value of $J_{f}$ varies between zero and unity, and represents the fraction of the particles which are burnt from initial diameter $d_{p i}$ to the critical diameter $d_{p c}$.

$J_{f}$ equals unity in case of BB grain burning because the value of acceleration due to projectile rotation is higher than $600 \mathrm{~g}$ during burning. Thus, $U / U_{0}$ will be constant against the acceleration level for a certain operating pressure. The burning rate is related to the gases pressure. So, $f$ is proportional to $\mathrm{F}_{\mathrm{ch}}{ }^{\alpha}$, i.e $f \propto P_{c h}{ }^{\alpha}$. But, the parameter $\eta$ characterizes the grain composition type, thus

$$
\eta f=\eta_{\infty} f_{\infty}\left(P_{c h} / P_{v}\right)^{\alpha} .
$$

Where, $\eta_{\infty} f_{\infty}$ is calculated at certain pressure $P_{0}$. 


\section{TRAJECTORY SIMULATION OF BB PROJECTILE}

The simulation of BB projectile trajectory is similar to that of an ordinary projectile. Figure (5) shows the forces acting on a typical artillery projectile during flight. Applying Newton's second law, the projectile equations of motion in the $x$ and $y$ directions will be:

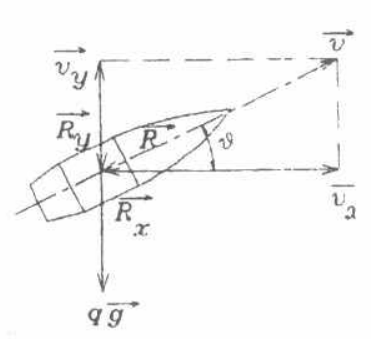

$$
q \frac{d v_{x}}{d t}=-R \operatorname{Cos} \theta, q \frac{d v_{y}}{d t}=-R \operatorname{Sin} \theta-g q
$$

Fig.5 Air resistance components acting on the projectile during fight

where $v_{x}$ and $v_{y}$ are the components of projectile velocity in the $x$ and $y$ directions, respectively, $t$ is the instantaneous time of flight, $R$ is the total air resistance force, $q$ is the projectile mass and $g$ is the gravitational acceleration. The air resistance force is given by the following equation:

$$
\mathrm{R}=\frac{1}{2} \rho_{\infty} \mathrm{v}^{2} \mathrm{SC}_{\mathrm{D}}(\mathrm{M}, \mathrm{Re})
$$

where $\rho_{\infty}$ is the upstream air density, $S$ is the projectile reference area. However, the drag reduction due to $B B$ must be calculated and subtracted from the total drag within BB grain burning. Figure (6) illustrates the drag coefficient of the projectile considered, with live and dummy BB.

Figure (7) illustrates the normalized trajectories $x / X_{\text {tab. }}$ ( where $X_{\text {tab }}$ is the tabulated range for the projectile with dummy $B B$ unit) in case of live and dummy BB projectiles. The range is increased by about $17 \%$ in case of live BB projectile.

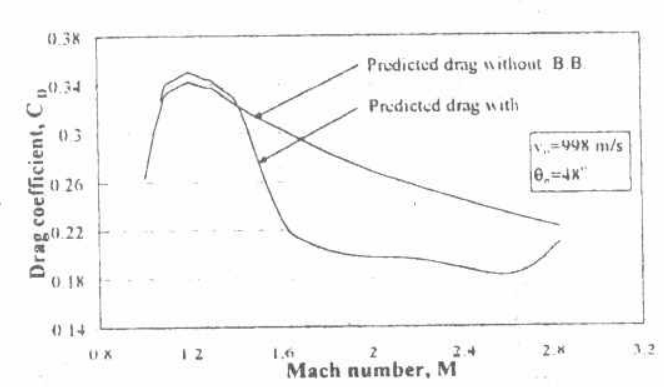

Fig. 6 Predicted drag coefficient of the projectile with dummy and live BB

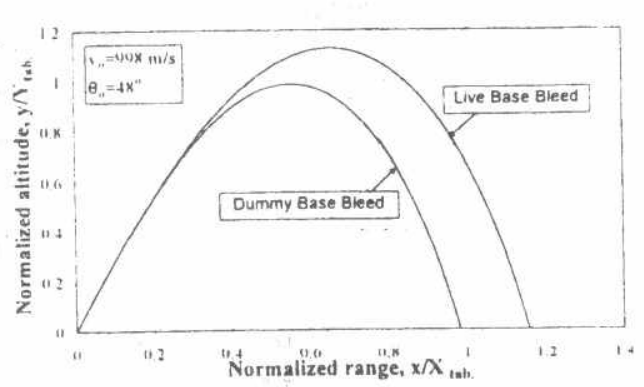

Fig. 7 Trajectories of the projectile $w$ th dummy and live BB

\section{RESULTS AND DISCUSSIONS}

In this section, discussion of the effect of some essential parameters on the projectile trajectory will be introduced. Predicted trajectory parameters will be compared with those measured experimentally. 


\subsection{RELATION BETWEEN PROJECTILE SHAPE AND BB}

A typical BB projectile must be characterized by long ogive and small boat-1.ail angle, because in this case base drag represents about $50 \%$ of the total drag, and appreciable amount can be reduced via BB.

Figure (8) shows the effect of ogive length on the amount of nose drag in relation to base pressure drag, as predicted by the present model. It is obvious that base drag is higher than nose drag at higher ogive lengths and Mach numbers less than 2.5. In such a case, the BB has a discernible effect on the range. On the contrary, in case of projectiles with short ogive, BB has limited effect on the range. Figure (9) illustrates the relationship between the base pressure and boat-tail drag coefficients at two different boat-tail angles $\left(\beta=3^{\circ}\right.$ and $\left.10^{\circ}\right)$. It is obvious that the boat-tail drag coefficient is much higher than the base pressure drag at subsonic and transonic regions for $\beta=10^{\circ}$. However, for $\beta=3^{\circ}$ the boat-tail drag coefficient is lower than the base pressure drag. So, the value of angle $\beta$ must be optimized in order to obtain the smallest drag coefficient and at the same time appreciable base pressure drag.

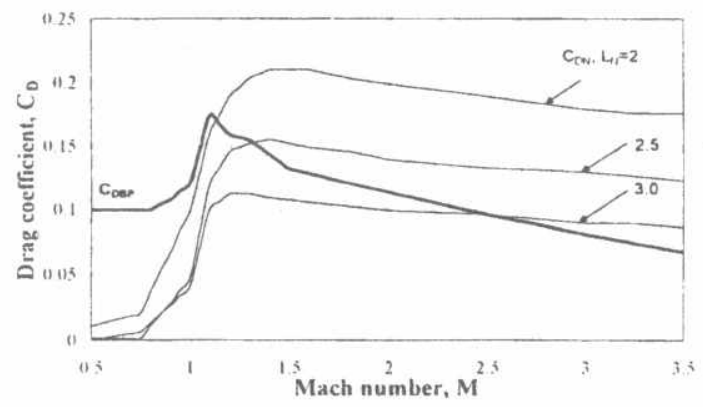

Fig.8 Relationship between nose drag and base drag for different ogive lengths

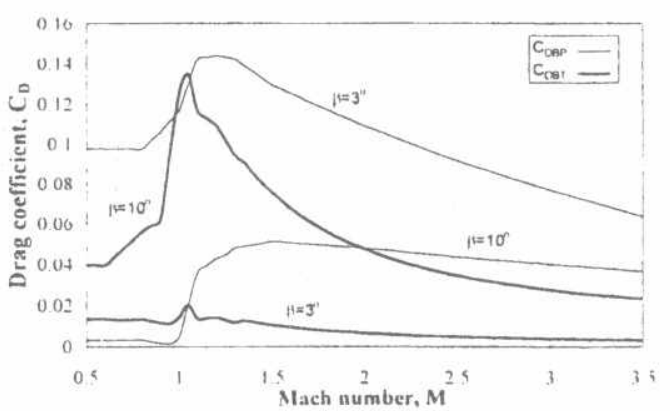

Fig. 9 Relationship between base drag and boat-tail drag coefficients for different boattail angles

From the previous discussion, it can be concluded that the improvement of $B B$ projectile shape does not only decrease the total drag, but also makes the ratio of the base drag to the total drag higher. As such, the reduction of base drag via $B B$ results in considerable percentage increase in range. Finally, the projectile must have the most appropriate geometrical shape before BB is installed.

\subsection{FACTORS AFFECTING BALLISTIC PERFORMANCE OF BB UNIT}

There are many factors which affect ballistic performance of BB unit. These factors are: (i) geometry of BB grain, (ii) base burning (static burning) rate of the grain composition, and (iii) Initial firing conditions. 


\subsubsection{Effect of BB Grain Geometry}

The geometry of the grain affects the mass flow rate from the nozzle, i.e. the bleeding parameter is changed with the change of grain geometry. Many experiments were conducted to get suitable shapes of the grain such that the bleeding parameter is maximized and, at the same time, not exceeding the value of $l_{\text {lim }}$ of base flow. The dimensions of the star point, cf. Fig. (10), have very important effect on the instantaneous burnt surface during projectile flight. Figures (11) to (14) illustrate the variation of normalized maximum range $\left(X / X_{\text {tab }}\right)$ due to changes in star point dimensions, where $X$ is the $B B$ projectile maximum range and $X_{t a b}$ is the maximum tabulated range of the projectile with dummy BB unit.
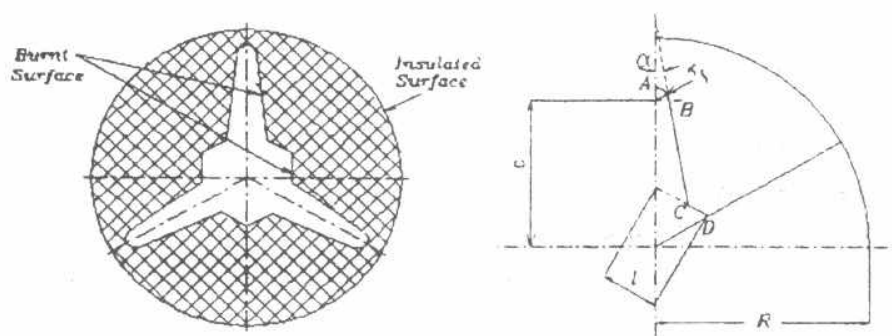

Fig.10 Geometry of the star point of the modified star grain form

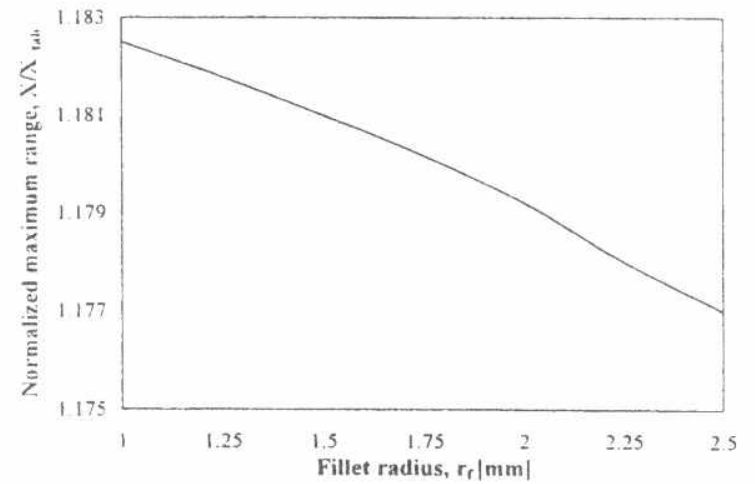

Fig. 11 Star point fillet radius $\left(r_{f}\right)$ versus normalized maximum range

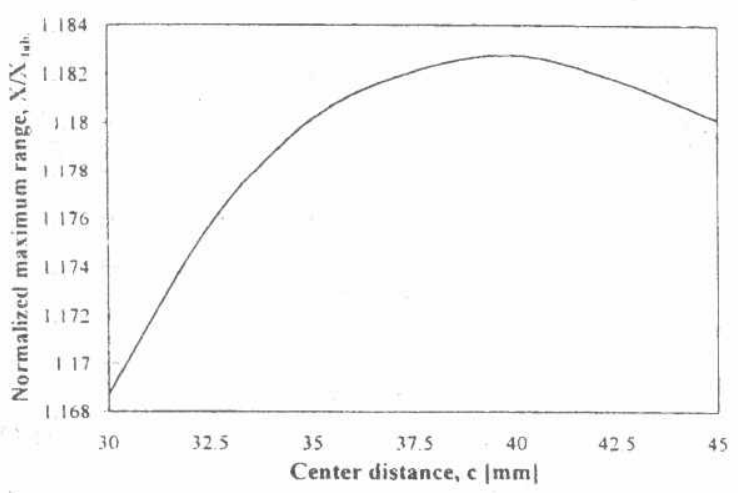

Fig13 Center distance (c) versus normalized maximum range

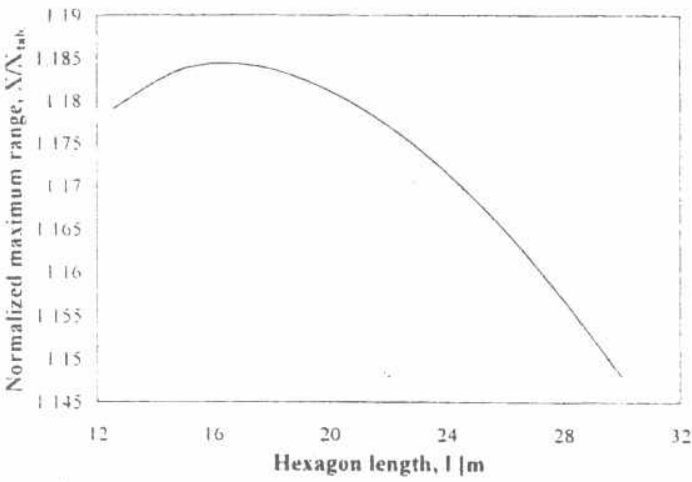

Fig. 12 Hexagon length (I) versus normalized maximum range

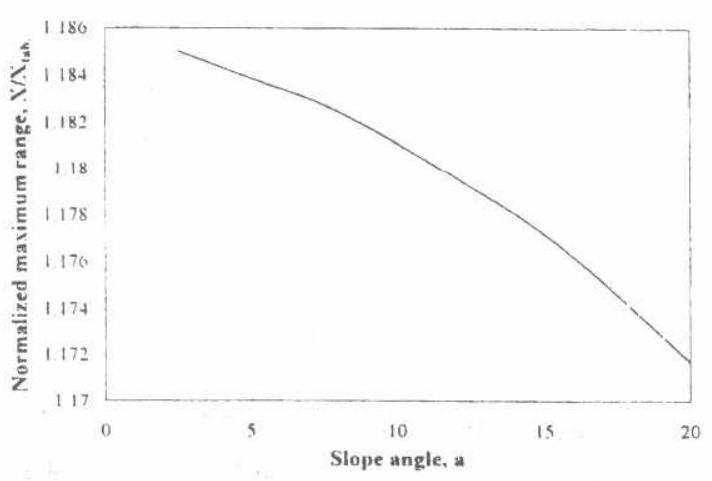

Fig. 14 Angle of star point slope $(\alpha)$ versus normalized maximum range 


\subsubsection{Effect of Burning Rate of BB Grain}

Naturally, the increase in burning rate of the grain composition decreases the bleeding time and consequently the duration time of base drag reduction. In other words, the increase in burning rate has an adverse effect on the BB unit performance. Figure (15) illustrates the variation of normalized maximum range $\left(X / X_{\text {tab. }}\right)$. with burning rate of the grain composition. It is shown that the normalized maximum range increases nonlinearly with the decrease of burning rate.

In case of projectile spin, the burning rate, $U$, of the grain increases. Figure (16) illustrates the change in range due to projectile spin for different types of grain compositions. It is seen that negligible effect is obtained for the compositions having values of $\eta f$ between 0 and 2.0. The limited effect of projectile spin on the total range reflects the approximate equality of the increase in bleeding parameter due to higher burning rate on one hand [ cf. Eq. (3)] and the decrease of bleeding time on the other hand. At the value of $\eta f=1.26$, the two effects are precisely equal and no change in range is obtained.

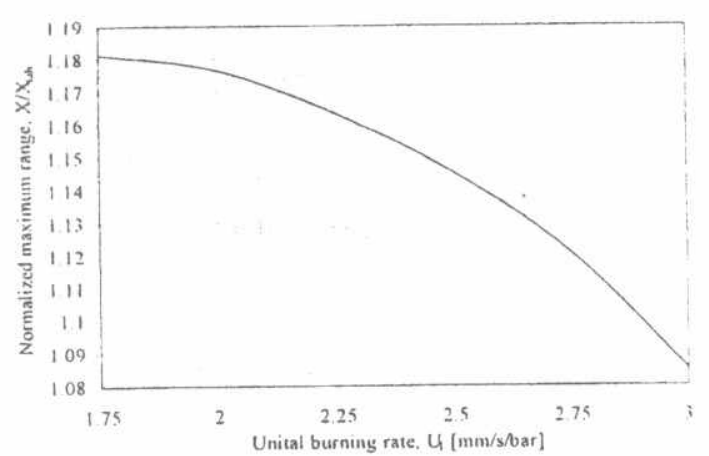

Fig. 15 Normalized maximum range versus base burning rate of the grain composition

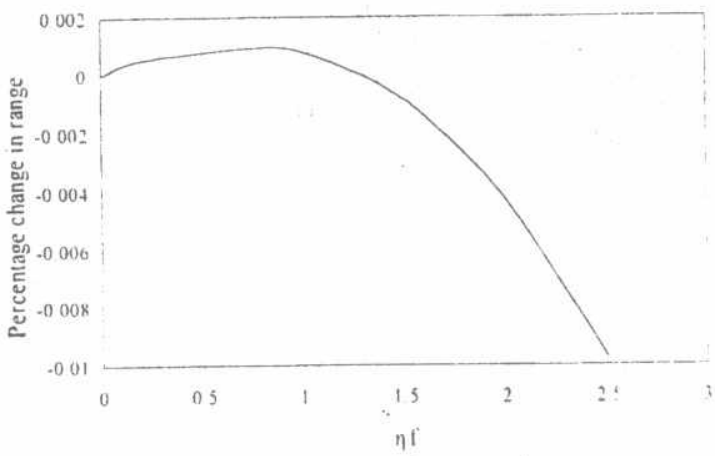

Fig. 16 Percentage change in rangle versus value of $\eta f$

\subsubsection{Effect of Initial Firing Conditions}

Figure (17) shows that the efficiency of BB increases with angle of fire. The percentage range increase is directly proportional to the increase of initial angle of fire in a non-linear fashion. The increase of BB unit performance may be expressed numerically by the reduced drag impulse, $S_{R I}$, which is given by the following equation [9]:

$$
\mathrm{S}_{\mathrm{RI}}=\int_{0}^{\mathrm{t}_{\mathrm{b}}} \frac{\Delta \mathrm{C}_{\mathrm{D}}}{\mathrm{C}_{\mathrm{D}}} \cdot \mathrm{dt}
$$

The area under the curve of $\Delta C_{D} / C_{D}$ versus time, Fig.(18), represents the reduced drag impulse. The higher this area, the better the $\mathrm{BB}$ ballistic performance will be. The change in initial firing angle reflects the effect on the $\mathrm{BB}$ projectile performance through the value of reduced drag impulse. 


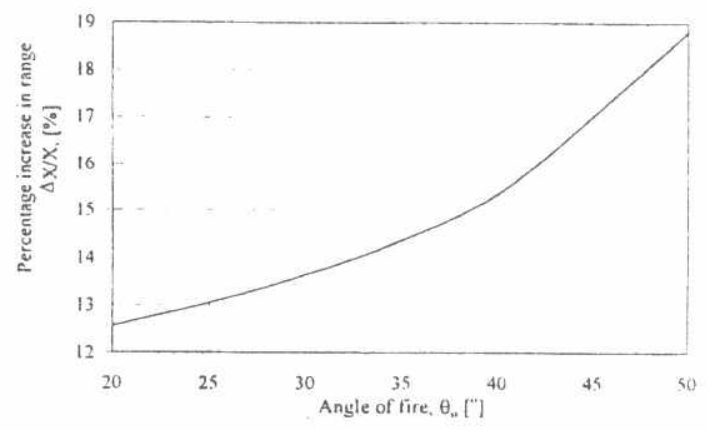

Fig. 17 Percentage of range increase versus initial angle of fire

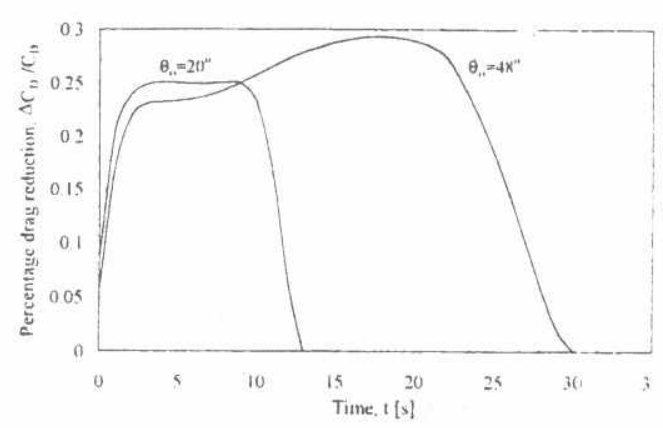

Fig. 18 Ratio of drag reduction versus time

\subsection{Validation of Drag Model for BB Projectiles}

Figure (19) depicts the measured drag coefficients of a group of the BB projectiles. The average drag coefficient is compared with the predicted counterpart, as shown in Fig. (20). In addition, the drag coefficient predicted for a similar projectile with inert BB charge is depicted for comparison. This figure shows that the predicted drag coefficient is always higher than the measured coefficient even aiter the end of BB flow. The percentage reduction in total drag ranges from $50 \%$ to $60 \%$ in the region of Mach number $1.6<M<2.6$. This region was found to give the best drag reduction for the star

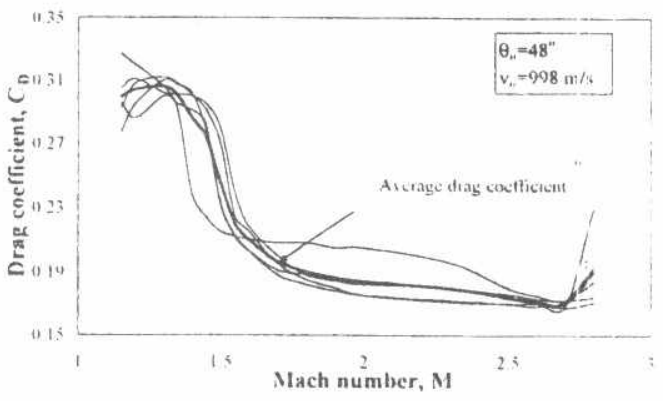

Fig. 19 Measured total drag coefficient versus Mach number grain shape. In this region of Mach number the value of the bleeding parameter approaches $I_{\text {lim. }}$ [cf. Fig. (2)].

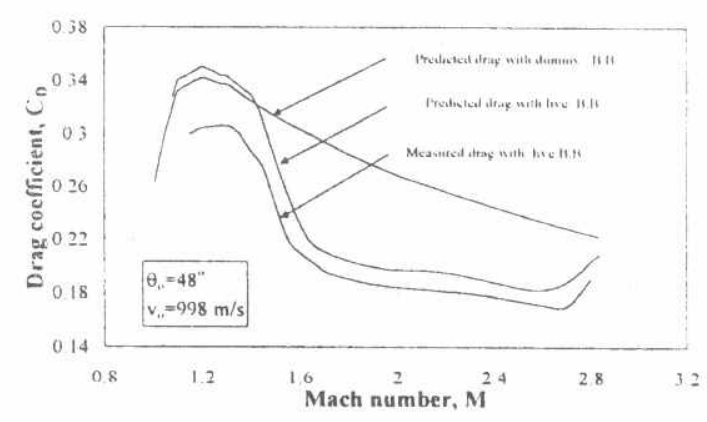

Fig. 20 Measured and predicted total drag coefficients, with live and dummy BB, versus Mach number

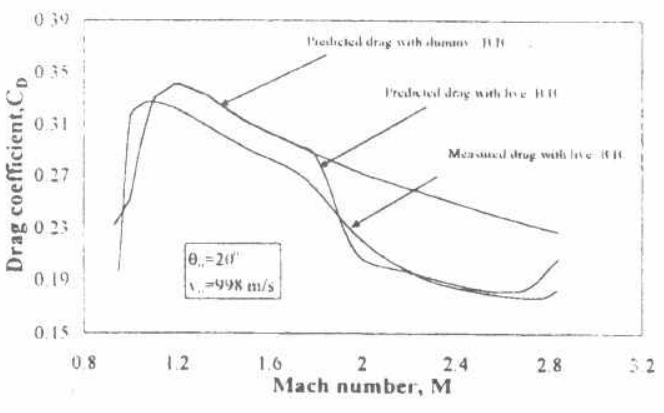

Fig. 21 Measured and predicted total drag coefficients versus Mach number

\section{CONCLUSIONS}

From the findings of this work, it is concluded that the shape of BB projectile must be improved to minimize air resistance to projectile motion. As such, base drag constitutes an appreciable contribution to total drag. Thus, 
reduction of base drag via BBing will have a great effect on the projectile range. One of the controlling parameters of $\mathrm{BB}$ unit performance is the bleeding parameter I. Moreover, bleeding time has a competitive effect on the total range of the $\mathrm{BB}$ projectile. Longer bleeding time with lower drag reduction may result in higher range. So, the expression of reduced drag impulse [9] is a proper representative parameter of the total effect of BB unit on the range.

The spin rate of the $\mathrm{BB}$ projectile increases the grain burning rate. Although the burning time is decreased due to projectile spin, the total range may not be affected by this decrease due to higher gas flow which results in higher base pressure drag reduction. The decrease of burning time of BB grain is not attributed to the projectile spin only, but may be related to the value of the initial firing angle as well. If the BB projectile is fired at lower elevation, the burning time will decrease due to higher air pressure at lower altitudes and vice versa. To conclude, the burning rate increase due to projectile spin has a negligible effect on the projectile range.

\section{REFERENCES}

[1] Karsten, P.A. (1998), "Long Range Artillery: The Next Generation," $17^{\text {th }}$ International Symposium on Ballistics, South Africa, Vol. I, pp. 133-141.

[2] J. Sahu and W. L. Chow (1988), "A Review of the Fluid Dynamic Aspects of the Effect of Base Bleed," First International Symposium on Special Topics in Chemical Propulsion, K. K. Kenneth and J. N. Fleming, Hemisphere Publisher Corp., New York, pp. 81-91.

[3] Chargelegue, D. and Couloumy, M. T. (1988), "Base Burn Projectile French Trajectory Model," First International Symposium on Special Topics in Chemical Propulsion, K. K. Kenneth and J. N. Flerning, Hemisphere Publisher Corp., New York, pp. 187-203.

[4] A. Zaki, H. Yakout, M.S. Abdel-Kader (1999), "Trajectory Simulation of Ogival-Boat-Tailed Projectiles," $8^{\text {th }}$ International Conference on Aerospace Sciences \& Aviation Technology (ASAT), M.T.C, Cairo, Egypt.

[5] Ding, Z., Liu, Y., and Chen, S. (1988), "A Study of Drag Reduction by Base Bleed at Subsonic Speeds," First International Symposium on Special Topics in Chemical Propulsion, K. K. Kenneth and J. N. Flening, Hemisphere Publisher Corp., New York, pp. 241-250.

[6] Jaramaz, S. and Injac, M. (1988), "Effect of Grain Characteristics on Range of Artillery Projectiles with Base Bleed," First International Symposium on Special Topics in Chemical Propulsion, K. K. Kenneth and J. N. Fleming, Hemisphere Publisher Corp., New York, pp. 143-157. 
[7] Gunners, N., Andersson, K., and Nilsson, Y. (1988), "Testing of Parts and Complete Units of the Swedish Base Bleed System," First International Symposium on Special Topics in Chemical Propulsion, K. K. Kenneth and J. N. Fleming, Hemisphere Publisher Corp., New Y'ork,
pp. 251-269.

[8] Sturm, E.J. and Reichenbach, R. E. (1970), "An Investigation of the Acceleration Induced Burning Rate Increase of Nonmetallized Composite Propellants," AIAA Journal, Vol. 8, No. 6, pp. 1062-1067.

[9] Guo, X. (1988), "Discussion of Two Important Parameters of Base Bleed Projectiles," First International Symposium on Special Topics in Chemical Propulsion, K. K. Kenneth and J. N. Fleming, Hemisphere Publisher Corp., New York, pp. 159-170. 